\title{
Evolution of convective systems across Hangzhou Bay during a sea-breeze-effect thunderstorm event
}

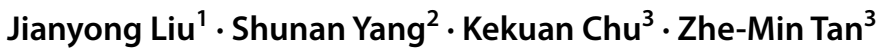

Received: 22 December 2017 / Accepted: 24 October 2018 / Published online: 8 November 2018

(c) The Author(s) 2018

\begin{abstract}
In this study, the impact of surface water body on the evolution of thunderstorm events crossing Hangzhou Bay is investigated based on the observations and numerical simulations. The organized convective systems crossing Hangzhou Bay usually weaken first after moving onto the water surface, and then re-intensify after landing onto southern coastline. The weakening of storm over the bay is mainly ascribed to the low water surface temperature, that is, the decreasing of water surface temperature is unfavorable for the development of storm. The re-intensification of storm over the southern coastline is due to the boundary layer convergence strengthening along the sea-land interface. For the organized thunderstorm, the enhancement of large-scale onshore wind can increase boundary layer convergence along both northern and southern coastlines, which leads to enhancement of convection and precipitations on the northern coastline.
\end{abstract}

\section{Introduction}

The large water body as a specific surface can impact the formation and evolution of convective system. Due to the thermal contrast between land and water, the water surface is usually predominately colder than the surrounding land during daytime hours in warm season, which may impact the evolution of the preexisting convective storms. In general, large water body could tend to suppress convection and precipitation when storms passing over them (e.g., Augustine et al. 1994; Scott and Huff 1996), and then can cause a $10 \%-20 \%$ decrease to downwind precipitation during summer season (e.g., Scott and Huff 1996).

Based on 111 convective storm events crossing Lake Erie during 2001-2009, Workoff et al. (2012) shown that almost storms tended to weaken over the lake. However, some storms exhibited a steady state or tend to develop under

Responsible Editor: M. Telisman Prtenjak.

Shunan Yang

shunanyoung@163.com

1 Ningbo Meteorological Observatory, Ningbo, Zhejiang, China

2 National Meteorological Center, China Meteorological Administration, Beijing, China

3 Key Lab of Mesoscale Severe Weather/MOE, School of Atmospheric Sciences, Nanjing University, Nanjing, China some environments. The storm intensity changing over lake and its sensitivity to atmospheric parameters both depend on the types of storms. In general, the isolated and cluster storms exhibited much greater weakening than organized linear or complex convective systems. Lericos et al. (2007) developed a conceptual model of how the land-water coastline affects the strength and structure of squall line. As the squall line moved from the water surface onto the land, the near-surface wind speed was reduced due to the friction of land. Moreover, the warm land induces a small onshore wind, which may further reduce the near-surface vertical wind shear in the inflow layer. As a result, the updraft will tilt to upshear and then weaken the squall line.

The severe storms could be triggered within the low-level convergence line (e.g., Ogura and Chen 1977; Wilson and Schreiber 1986). The boundary layer (hereafter BL) convergence and low-level vertical wind shear induced by the sea-land breeze are two important facts for the controlling of trigging and evolution of convective systems when they across large water body. The thermal contrast between land and water and the BL friction could change the BL's structure, and then further influence the evolution of organized convective systems (e.g., King et al. 2003; Lericos et al. 2007; Mazón and Pino 2013).

The sea breezes are powerful generators of boundaries, and the role of the sea-breeze circulation, including the seabreeze front, in triggering convection has long been recognized (Byers and Rodebush 1948; Leopold 1949; Pielke 
1974). The sea-breeze circulation is a product of thermodynamic contrast between land and ocean, consisting of onshore flow during daytime (sea breeze) and offshore flow at night (land breeze) (e.g., Simpson 1994). The low-level onshore flow within the sea-breeze circulation can advect wet sea air into land, and a convergence zone between seamodified air and unmodified air forms, which could provide both moisture convergence and lift to initiate convection (King et al. 2003). As the interface between sea and land, the irregular coastline can both affect the triggering and distribution of convection and precipitation along a sea-breeze front (Neumann 1951; Purdom 1976; Abbs1983; Baker et al. 2001; Mazón and Pino 2013).

In the present study, through observations and numerical simulations, we investigate how the strength and structure of convective system crossing Hangzhou Bay in East China evolved when the thunderstorm passed across colder water surface and when it moved on land once again. The impact of large water body and thermal contrast between sea and land on the evolution of the storm is discussed. In Sect. 2, we introduce data and numerical model. The results of numerical simulations are presented in Sect. 3, followed by discussions in Sect. 4. Conclusions are given in Sect. 5.

\section{Observations and numerical model}

\subsection{Observations and data}

The bugle-shape Hangzhou Bay (hereafter HB) is a large water body in northeastern Zhejiang province, China, with the length of the bay mouth being $95 \mathrm{~km}$ and the average south-north span being more than $40 \mathrm{~km}$ (Fig. 1a). The east side of HB is the East China Sea and the west side is Hangzhou City. The terrain of both north and south side of $\mathrm{HB}$ are relatively flat with an average elevation of less than $250 \mathrm{~m}$.

In this study, observations and numerical simulations are both used to investigate the HB's impact on the evolution of
Fig. 1 a Hangzhou Bay region with topography depicted by the color shading every $250 \mathrm{~m}$. The average south-north span of the bay is $40 \mathrm{~km}$. The red star shows the location of the radar station in Ningbo. b Configuration of the three nested model domains (D1, D2, and D3) with 12-, 3-, and 0.75-km horizontal grid resolutions, respectively. c Detailed innermost domain: thick curve indicates regions where surface friction is altered in experiment Fric, and dark dots represent stations with intensified easterly wind speed in experiment Bogus. The red point $A$ is the reference points for analysis of thermodynamic variables over Hangzhou Bay
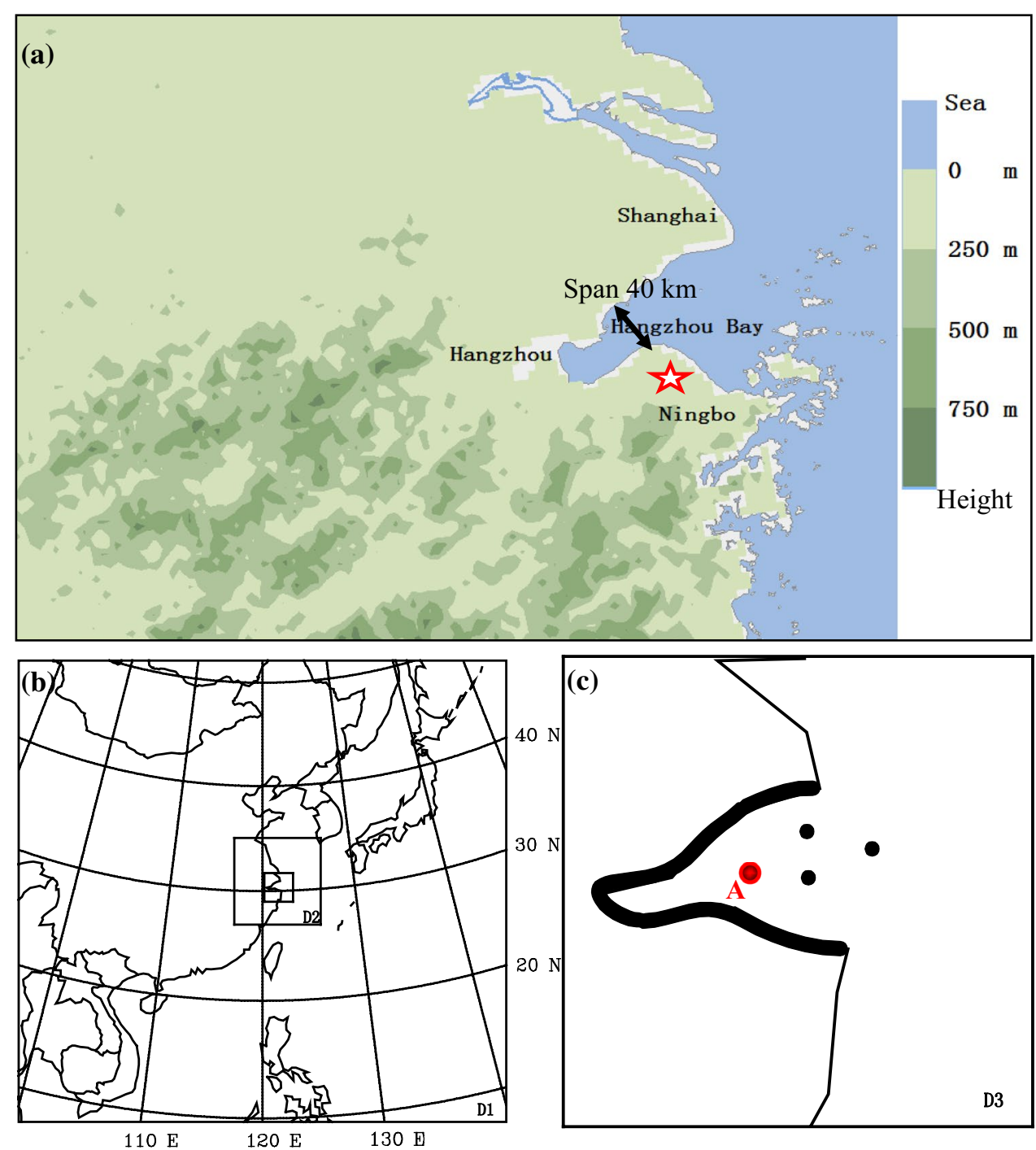
the thunderstorm crossing HB. A WSR88d Doppler Radar located at $30 \mathrm{~km}$ south of HB south bank (Fig. 1a), which provided radar reflectivity data for observational analysis. The regional automatic meteorological station observations with a horizontal resolution of about $10 \mathrm{~km}$ are used for the precipitation and surface wind analysis and data assimilation.

The initial and boundary conditions of the simulation are derived from the $0.5^{\circ} \times 0.5^{\circ}$ Global Forecast System (GFS) model operational analysis data of the National Centers for Environmental Prediction (NCEP) with 6-h time interval.

\subsection{Numerical model and experimental design}

For numerical simulations, the Advanced Research WRF (ARW) version 3.2 is implemented. We employ here three two-way interactive nesting model domains (D1, D2, and D3; see Fig. 1b) with 12-, 3-, and 0.75-km horizontal resolution, respectively. The $0.75-\mathrm{km}$ resolution inner domain (Fig. 1c) has the grids of $401 \times 401$. There are $35 \sigma$ layers in the vertical direction for all the domains with the model top defined at $50 \mathrm{hPa}$. The modified version of the Kain-Fritsch cumulus convective parameterization scheme (Kain and Fritsch 1990, 1993; Kain 2004) is used in the outermost domain (D1); while for the inner two domains (D2 and D3), no convective parameterization is used since the explicit microphysics (Thompson et al. 2008) is at play. The Thompson microphysics scheme and the YSU planetary boundary layer parameterization (Hong et al. 2006) are used for all three domains. WRF model can reproduce the seabreeze convergence and small-scale phenomena (e.g., Comin et al. 2015).

To investigate the impact of $\mathrm{HB}$, especially its cold-water surface and BL convergence, on evolution and structure of convective systems crossing HB, five sensitivity experiments with different underlying surface are conducted (Table 1). They are experiments replacing HB's water surface with land (NoBay), decreasing or increasing water surface temperature of $\mathrm{HB}$ ( $\mathrm{TmpN}$ and $\mathrm{TmpP})$, intensifying easterly wind speed over the Bay (Bogus), and increasing surface friction along the coastline (Fric).
Specifically, in experiment NoBay, the water body of HB is replaced by irrigated cropland in the numerical model; and its soil temperature, vegetation coverage and other ground information are all the same as that of the coastal areas near HB. Through the comparison between the results of the control experiment (CTRL) and those of NoBay, the overall impacts of $\mathrm{HB}$ on storm evolution can be detected. In experiments TmpN and TmpP, only the surface temperature in HB is changed, which can isolate the influence of cold water surface temperature on the evolution of organized convective systems. The surface temperature perturbation amplitude of $\mathrm{HB}$ is set to $2 \mathrm{~K}$, and on the east side of HB where it merges with the East China Sea, surface water temperature perturbation amplitude decreases to zero linearly. In experiment Bogus, the easterly surface wind speed within HB is increased by assimilating bogus data through WRF-3DVar at locations shown in Fig. 1c. For the artificial observations that are assimilated in experiment Bogus, the easterly wind speed and sea-level pressure are increased by $2 \mathrm{~ms}^{-1}$ and $1.5 \mathrm{hPa}$, respectively. To reduce sea-land breeze circulation around HB, as shown in Fig. 1c, the experiment Fric is implemented through increasing the roughness along the interface between HB and land in the numerical model. The underlying surface type of the grid points nearby HB is "irrigated cropland". In experiment Fric, the underlying surface type is also set to "irrigated cropland" but the surface roughness along the coastline of $\mathrm{HB}$ is changed from 0.18 (in CTRL) to 0.5. In a word, experiments Fric and Bogus are implemented for assessing the impacts of sea-land breeze intensity and environmental easterly wind on the evolution of convective systems around $\mathrm{HB}$, respectively.

\subsection{Case overview}

The change of thunderstorms' intensity is greatly as crossing HB, which brings great uncertainties to forecast. In this paper, based on radar reflectivity and integrated observations of surface rainfall, a compact organized linear or complex convective system crossing HB and lasting for at least $3 \mathrm{~h}$ is defined as the HB -influencing case. The isolated thunderstorms are excluded in this study, because it is hard to track their intensity changes over the HB due to the short
Table 1 Numerical experimental design

\begin{tabular}{ll}
\hline Experiment & Description \\
\hline CTRL & Control experiment \\
NoBay & Replacing water surface of Hangzhou Bay with cropland \\
TmpN & -2 K perturbation added to surface temperature of Hangzhou Bay \\
TmpP & 2 K perturbation added to surface temperature of Hangzhou Bay \\
Bogus & Increasing easterly wind speed and sea level pressure over Hangzhou Bay to amplify \\
& boundary convergence \\
Fric & Increasing friction along Hangzhou Bay's coastline to reduce boundary layer convergence \\
\hline
\end{tabular}


life cycles. The analysis revealed that 11 organized thunder storms have passed over HB from 1 July 2006 to 31 July 2010 (Table 2). Among these convective systems, 64\% weakened or dissipated, while $36 \%$ maintained their intensity over HB.

An organized thunderstorm generated at the northwest side of HB at 1600 LST July 4, 2010 is chosen for detailed analysis. The storm experienced the following strength changes as passing over the HB: intensifying over the coastline, weakening over colder water surface, and finally strengthening again after landing on the south side of HB. The evolution of storm is highly representative, whose process accounts for about $64 \%$ of the organized thunderstorms over the HB. At the same time, the large-scale environment enforce of this case is relatively weak, and the thermal

Table 2 Intensity evolution of convective systems during their moving over Hangzhou Bay and their landing on the other side of the Bay

\begin{tabular}{|c|c|c|}
\hline Time of cases & $\begin{array}{l}\text { Moving } \\
\text { overwater } \\
\text { surface }\end{array}$ & $\begin{array}{l}\text { Landing on } \\
\text { the other } \\
\text { side }\end{array}$ \\
\hline From 0700LST to 1200LST 5 Jul. 2006 & Weakened & Intensified \\
\hline $\begin{array}{l}\text { From 0600LST to 1700LST } 22 \text { Aug. } \\
2006\end{array}$ & Weakened & Intensified \\
\hline $\begin{array}{l}\text { From 1600LST to 2100LST } 25 \text { Aug. } \\
2006\end{array}$ & Weakened & Sustained \\
\hline $\begin{array}{l}\text { From 1500LST to 2100LST } 20 \mathrm{Jul} . \\
2007\end{array}$ & Sustained & Intensified \\
\hline $\begin{array}{l}\text { From 0700LST to 1200LST } 21 \mathrm{Jul} . \\
2007\end{array}$ & Weakened & Intensified \\
\hline $\begin{array}{l}\text { From 1200LST to 1800LST } 28 \text { May } \\
2008\end{array}$ & Weakened & Intensified \\
\hline From 1300LST to 1900LST 5 Sep. 2008 & Sustained & Intensified \\
\hline From 1600LST to 2100LST 5 Jun. 2009 & Sustained & Sustained \\
\hline $\begin{array}{l}\text { From 1400LST to 2000LST } 20 \text { Jun. } \\
2009\end{array}$ & Weakened & Sustained \\
\hline $\begin{array}{l}\text { From 1500LST to 1900LST } 30 \text { Jun. } \\
2010\end{array}$ & Sustained & Intensified \\
\hline $\begin{array}{l}\text { From 1600LST to 2000LST 04 Jul. } \\
2010\end{array}$ & Weakened & Intensified \\
\hline
\end{tabular}

instability is strong, so that it can be used for better analysis of sea-land breeze effect. The thunderstorm occurred north of 500-hPa subtropical anticyclone with northwesterly wind (Fig. 2a), which led the storm moving southeastward and passing over HB from the north side to the southeast side.

During that time, the south-north temperature contrast around $\mathrm{HB}$ near $30^{\circ} \mathrm{N}$ was very small at $500 \mathrm{hPa}$ and $850 \mathrm{hPa}$ (Fig. 2a, b). But there were distinct differences in the dewpoint depression, resulting in a dry line with wet air on the north side and dry one on the south side. The dewpoint depression was less than $4 \mathrm{~K}$ on the north side of $\mathrm{HB}$ and more than $16 \mathrm{~K}$ on the south side of $\mathrm{HB}$ at $500 \mathrm{hPa}$. It was indicated by the sounding of Hangzhou city that environmental condition near HB was relative dry in the low level and relative wet above before the thunderstorm occurred (Fig. 3). Calculations of physical variables showed a value of $1450 \mathrm{JKg}^{-1}$ for the convective available potential energy (CAPE), a value of $44 \mathrm{~K}$ in the $\mathrm{K}$-index (KI) and a value of $-4.5 \mathrm{~K}$ in the lifted index (LI) at Hangzhou at 0800 LST 4 July, which indicated strong unstable conditions near HB. These environmental conditions were all in favor of the generation and development of convective systems and the dry line. The "dry-below-wet-above" vertical distribution of moisture was likely to trigger the formation of strong thunderstorm. Observations of 2-m temperature (Fig. 4) showed that the temperature contrast between sea surface (point A) and land (point B) increased gradually from 0800 to $1400 \mathrm{LST}$ with the 2-m temperature growth from 4 to $7{ }^{\circ} \mathrm{C}$ (Fig. 4). The horizontal wind speed over HB water surface changed from southerly wind to easterly wind, which was favorable for the enhancement of BL convergence along the coastline. This was a distinct diurnal variation in sea-land breeze.

Radar reflectivity indicated that the thunderstorm, which was formed by the merging and strengthening of several scattered convections around Taihu Lake on northwest of $\mathrm{HB}$, organized into a band-shape convective system and moved southeastward quickly under the combined effects of upper-level leading wind and inflow behind the thunderstorm (not shown). The mean moving speed of the thunderstorm
Fig. 2 Geopotential height at $500 \mathrm{hPa}$ a and $850 \mathrm{hPa}$ b (contour; interval 2 dagm), dewpoint depression (shaded; interval $4 \mathrm{~K})$, temperature $\left({ }^{\circ} \mathrm{C}\right)$ and wind (full bar for $4 \mathrm{~ms}^{-1}$ ) measured by meteorological sounding at 0800 LST 4 July 2010

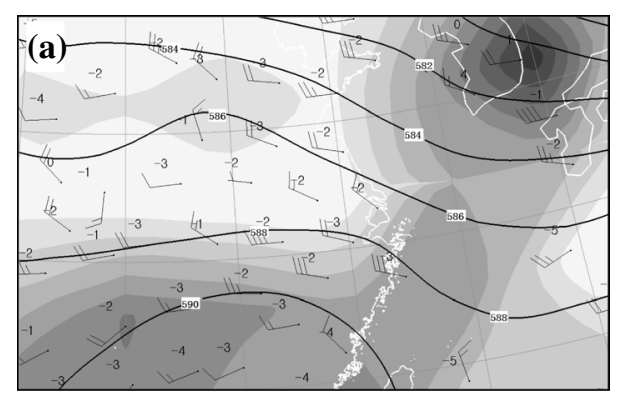

$100^{\circ} \mathrm{E}$ $120^{\circ} \mathrm{E}$

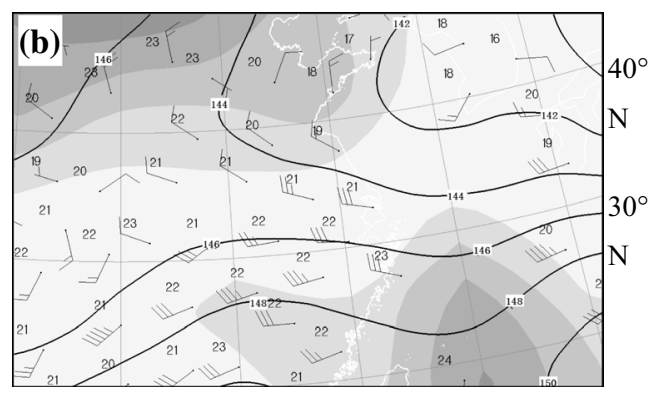

$120^{\circ} \mathrm{E}$ 
Fig. 3 The sounding of temperature (black line) and dew point temperature (gray line) at Station Hangzhou at 0800 LST 4 July 2010 (Data from NCEP reanalysis)

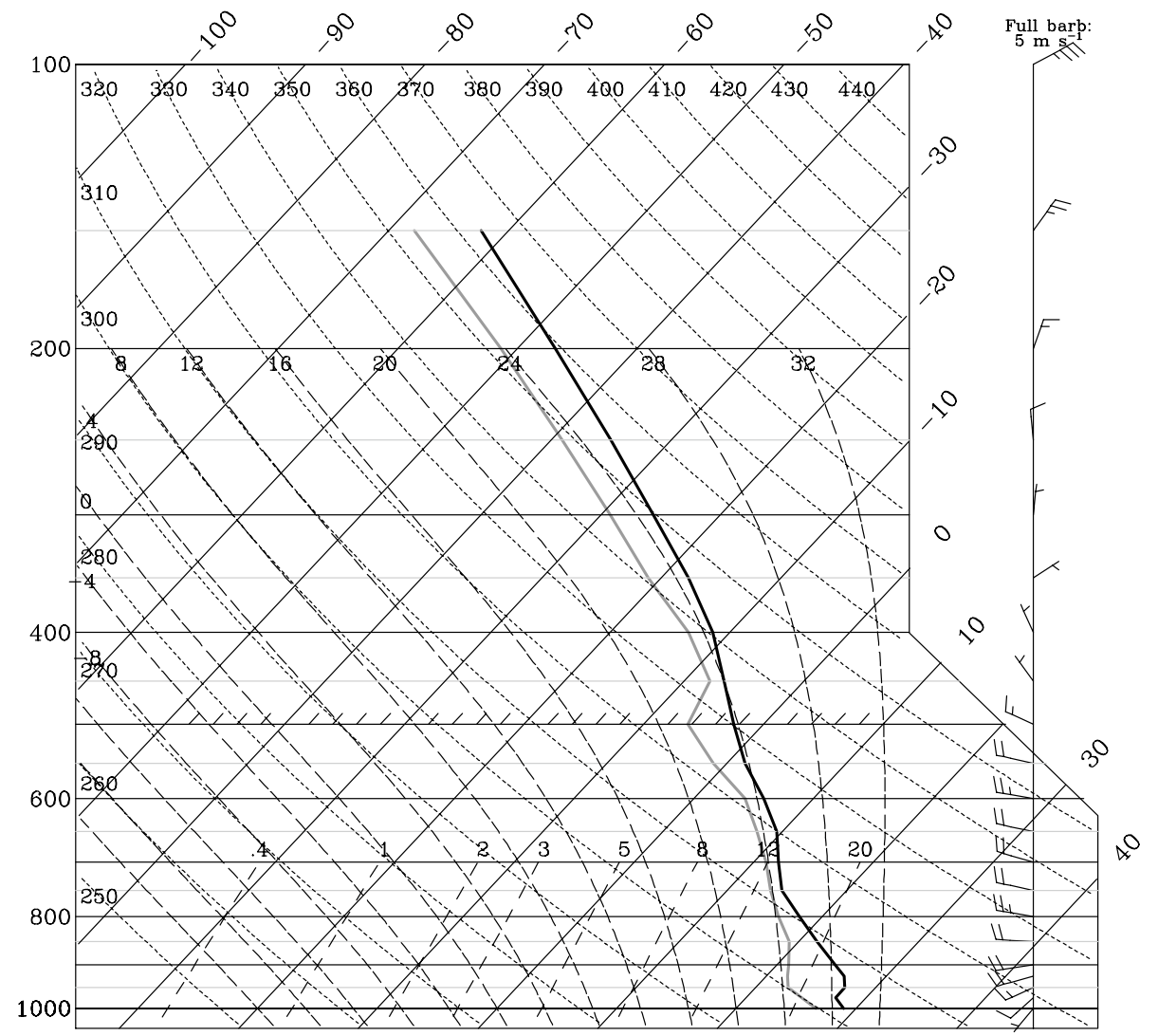

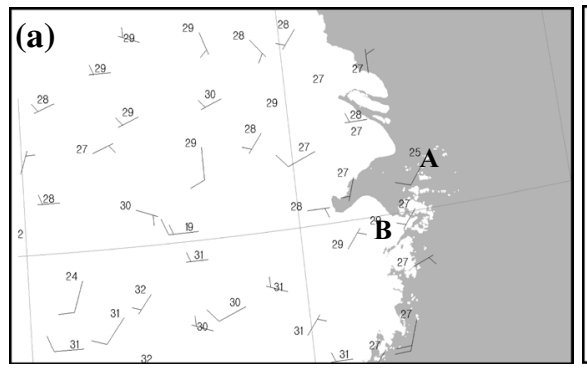

$120^{\circ} \mathrm{E}$

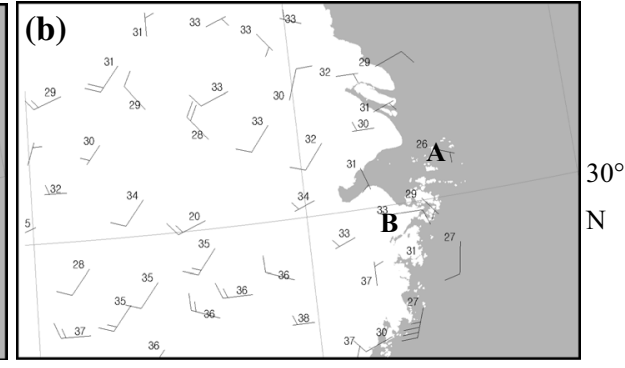

$120^{\circ} \mathrm{E}$ was about $14 \mathrm{~ms}^{-1}$, faster than the 2-min-averaged wind speed on the surface; this was favorable for convergence at the leading edge of thunderstorm. Both the maximum radar reflectivity and the coverage range of $40 \mathrm{dBZ}$ reflectivity of the thunderstorm were the strongest as it approached the north shore of $\mathrm{HB}$, and became the weakest after moving on to water surface (Fig. 5). The thunderstorm has an obvious bow-echo with a length of more than $200 \mathrm{~km}$. The left part of the bow-echo (elliptical area in Fig. 5) moved over HB water surface and weakened gradually, then landed on the south side of HB and intensified again. For example, before entering the $\mathrm{HB}$, the maximum radar reflectivity was about 50-60 dBZ along the north shore of HB (Fig. 5b), and it decreased to $40-50 \mathrm{dBZ}$ as the storm moved over the water surface (Fig. 5c). After landing on the south side of
$\mathrm{HB}$, the radar reflectivity of the storm developed once again to $50-60 \mathrm{dBZ}$, but its coverage range was comparatively smaller (Fig. 5d).

Figure 6 shows the observed accumulated precipitation and maximum surface wind speed during the event at each station from 1500 LST to 2200 LST 4 July 2010. It was illustrated that the large amount of rainfall appears on the two banks of $\mathrm{HB}$, while the precipitation over HB was relatively smaller (Fig. 6a). This was consistent with the intensity evolution of the mesoscale convective system as passing through HB. The largest maximum wind speed is located on water surface of $\mathrm{HB}$, followed by the northern coast of HB (Fig. 6b). The wind speed along the southern coast of HB decreased gradually. The distribution of maximum wind speed was not completely consistent with the variation of 


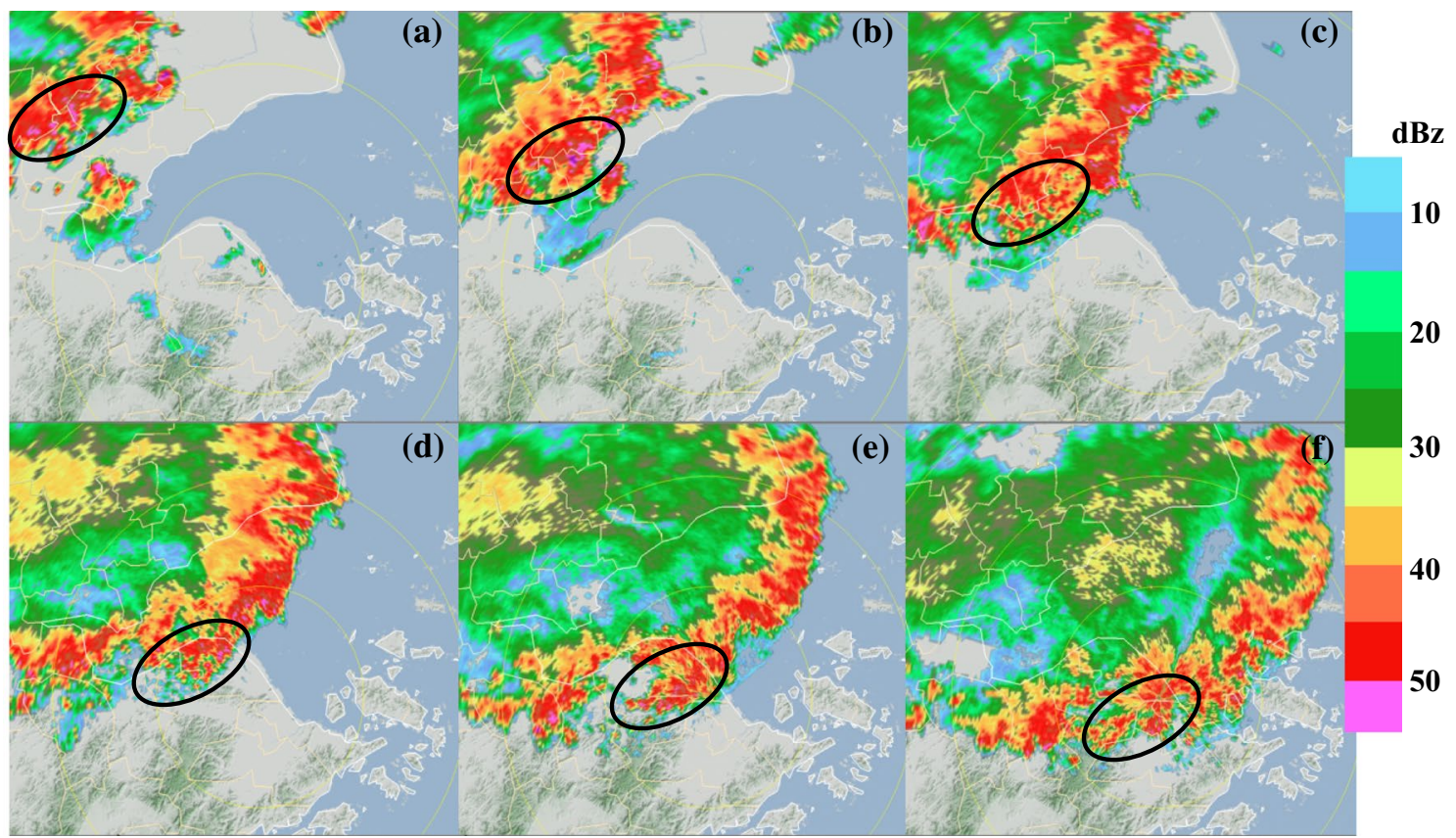

Fig. 5 Radar reflectivity observed at the $1.5^{\circ}$ elevation level, Elliptical area represents the part of the thunderstorm crossing Hangzhou Bay. a-f are from 1700 LST to 1930 LST 4 July 2010 with 30-min time interval

Fig. 6 a Accumulated precipitation ( $\geq 5 \mathrm{~mm}$, shading) and $\mathbf{b}$ maximum wind speed ( $\geq 8 \mathrm{~ms}^{-1}$, shading) observed by regional automatic meteorological stations during the event from 1500 LST to 2200 LST 4 July 2010
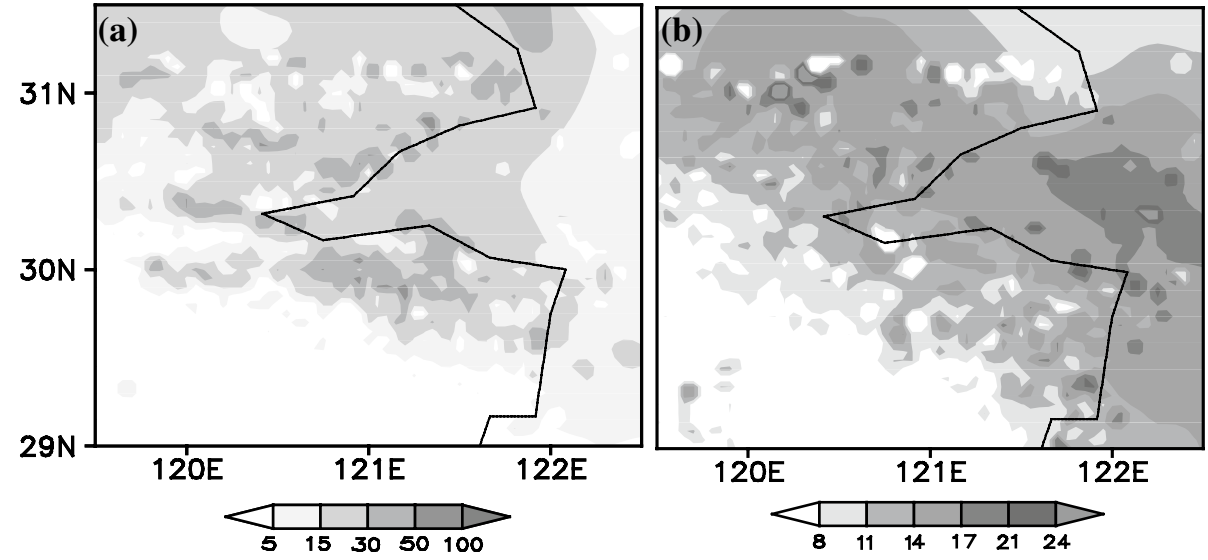

radar echo in Fig. 5, which may be influenced by the boundary friction contrast between land and water.

\section{Results}

After $2.5 \mathrm{~h}$ of integration (at $1630 \mathrm{LST} 4 \mathrm{July}$ ), the thunderstorm has developed on the north shore of HB in CTRL (Fig. 7a). Distinct sea-land breeze could be seen on the north shore of $\mathrm{HB}$. As a result, BL convergence existed near the northern coastline of $\mathrm{HB}$, and it could be further strengthened by the southeasterly wind above the water surface of HB; so, the thunderstorm could keep on intensifying as it just arrived over HB (Fig. 7b). After that, the thunderstorm traveled over the cold water surface, and its intensity weakened (Fig. 7c, d) due to low surface temperature over HB. Finally, when the thunderstorm made its landing on the south shore, the convective systems strengthened once more (Fig. 7e, f). BL convergence caused by the northwesterly inflow on the rear side of the thunderstorm and the southeasterly wind above the HB surface was the main factor strengthening the convective systems as the thunderstorm landed on the southern coastline. The intensity variation of the simulated thunderstorm is basically same as the observations (Fig. 5) but with a time-lag of about one hour.

The CTRL simulation also produces the observed precipitation distribution around HB very well, with heavier precipitation on both sides of the sea shore than over HB 


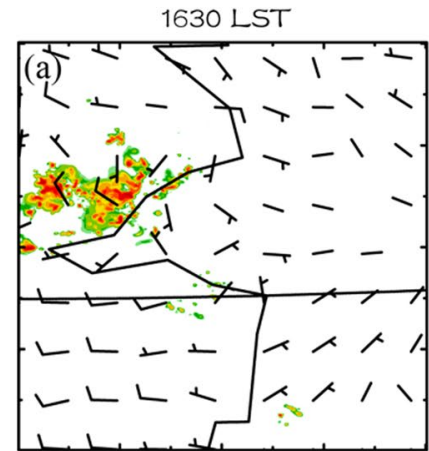

1830 LST

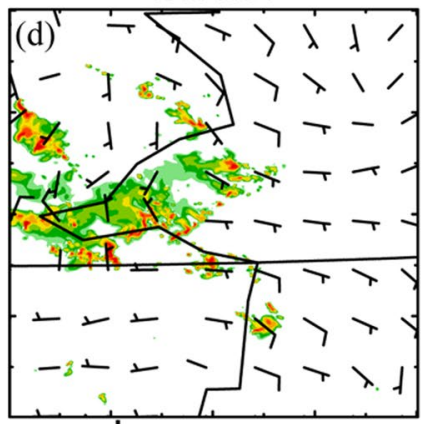

$121^{\circ} \mathrm{E}$

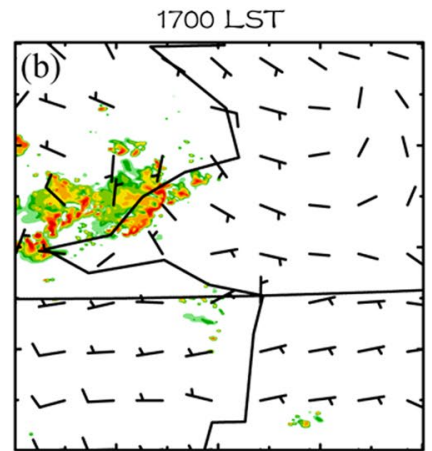

1900 LST

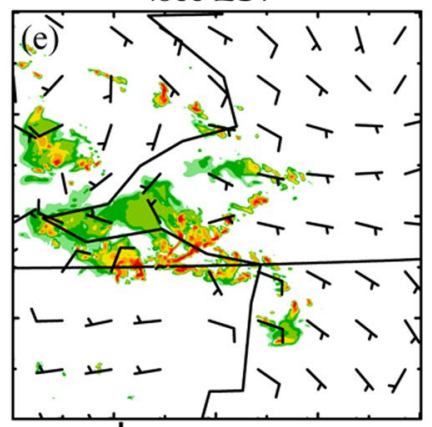

$121^{\circ} \mathrm{E}$

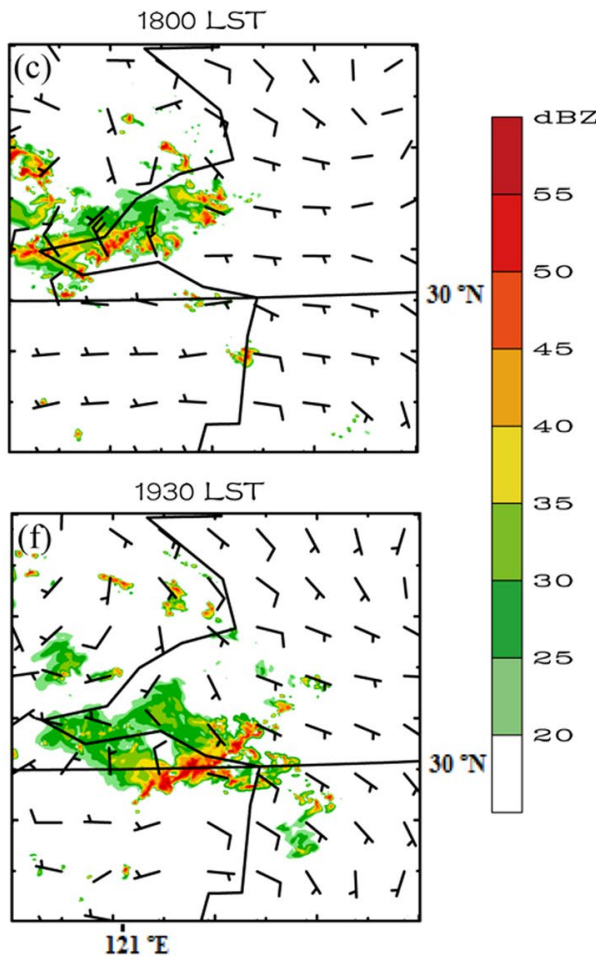

Fig. 7 Simulated 700-hPa radar reflectivity (dBZ) and 10-m horizontal wind (full bar for $2 \mathrm{~ms}^{-1}$ ) in control experiment (CTRL) at a 1630, b 1700, c 1800, d 1830, e 1900, and f 1930 LST 4 July 2010

(not shown), although the simulated areas of strong precipitation on the sea shore were located a bit eastward compared to the observation. The precipitation mainly existed on the near-shore region of the northern coastline and on the inland region of the southern coastline, with the maximum total precipitation being 30-50 $\mathrm{mm}$ during this event.

For accessing the overall impacts of $\mathrm{HB}$ on the evolution of storm, the underlying water surface of $\mathrm{HB}$ was replaced by irrigated cropland in experiment NoBay, and then the related evolution of convective systems is shown in Fig. 8a-c. Convective systems in NoBay remained intensifying rather than weakened in CTRL when it cross the original $\mathrm{HB}$ region. The regions with the strongest strengthening of convective intensity were located at the easternmost of the artificial cropland, which became the new boundary between land and sea. Furthermore, when the convective systems in NoBay passed over the original southern coastline of HB, the intensity of the storm did not strengthen compared with that in CTRL. In terms of 10-m horizontal wind, the BL convergence and the sea-land breeze in NoBay moved eastward and the BL convergence along the original coastline weakened compared with that in CTRL (Fig. 9a, b), resulting in the shift of location of convection developing. At the same time, due to the change of underlying surface properties, the isolated convection near HB started earlier and the wind field structure in the bay area has been changed. The area of the largest wind differences (Fig. 9a, b) corresponded very well with the strong radar echo area in Fig. 8a-c. The inflow and outflow of thunderstorms were the main factors affecting the deviation of wind field in the convective area in case of weak environmental wind. The land-sea-breeze wind speed was relatively smaller in Nobay, and its influence was more obvious on undeveloped convection area. Compared with CTRL, precipitation in NoBay was obviously increased in the central and eastern parts of the original HB, while weakened along the south shore (Fig. 10a). The average precipitation in NoBay was equivalent to that in CTRL, but the maximum precipitation is about $36.9 \mathrm{~mm}$, which is smaller than $52.7 \mathrm{~mm}$ in CTRL and $42.7 \mathrm{~mm}$ in observation (Table 3). It is noteworthy that at the offshore of HB northern coastline, precipitation in NoBay also decreased compared with that in CTRL, which was caused by the lack of BL convergdeep convection can be influencedence induced by sea-land breeze (Fig. 9a, b).

The water surface is usually predominately colder than land in the daytime during summer season. The surface temperature difference between $\mathrm{HB}$ and its surrounding seashore usually is up to $6-8 \mathrm{~K}$, which is in favor of seebreeze front formation. As shown in experiment TmpN, the decreasing of sea surface temperature (SST) over HB can suppress evolution of convective systems. Under the pre-existing relative low SST, the $\pm 2 \mathrm{~K} \mathrm{SST}$ perturbation 
Fig. 8 Simulated 700-hPa radar reflectivity $(\mathrm{dBz})$ and $10-\mathrm{m}$ horizontal wind difference (full bar for $2 \mathrm{~ms}^{-1}$ ) between sensitivity experiments and control experiments (CTRL). a-c: NoBay, $\mathbf{d}-\mathbf{f}$ : TmpN, $\mathbf{g}-\mathbf{i}$ : TmpP, $\mathbf{j}-\mathbf{l}$ : Fric, $\mathbf{m}-\mathbf{0}$ : Bogus at 1630, at 1800, and 1930 LST 4 July 2010, respectively

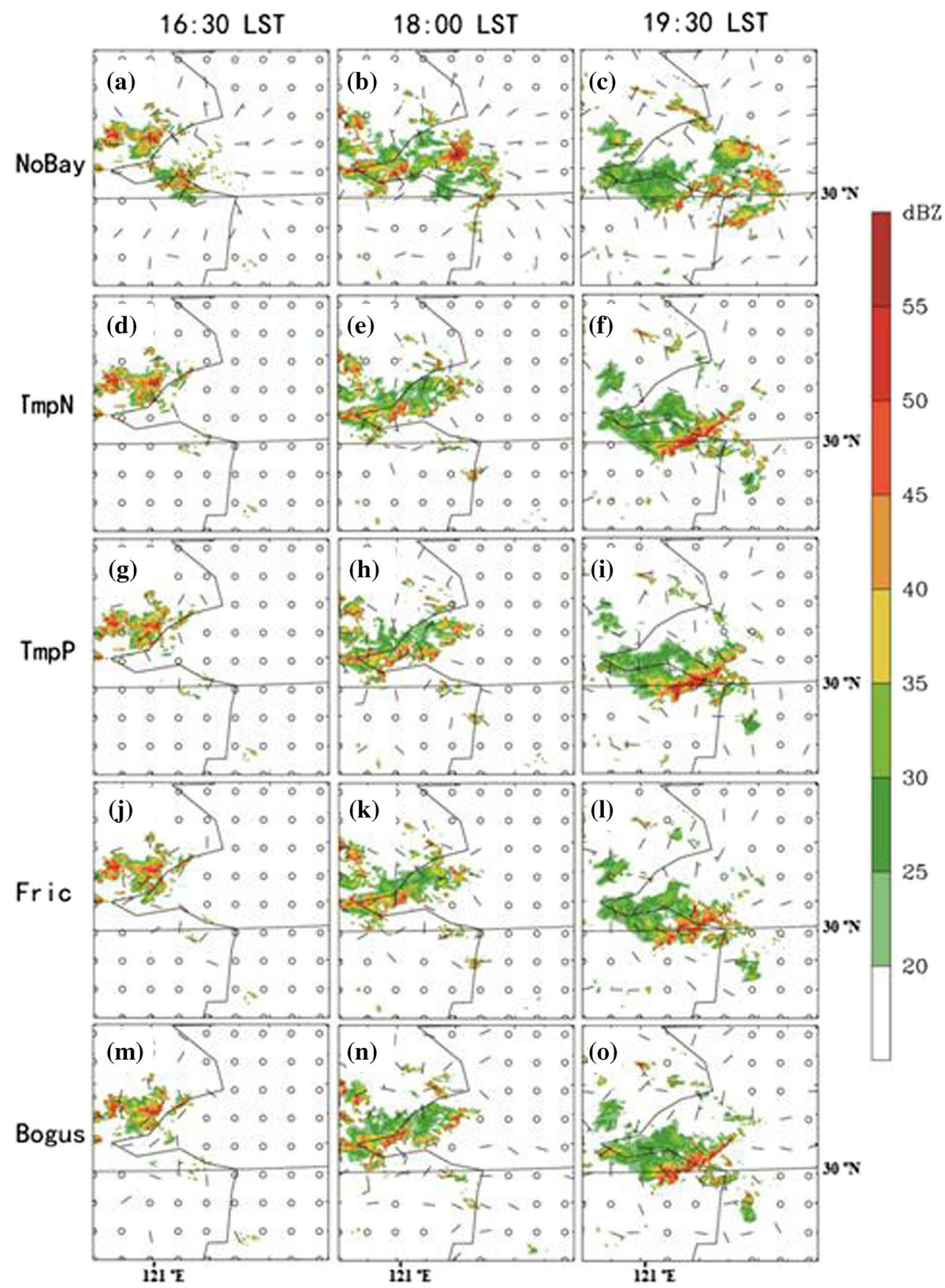

has relative weak impact on radar reflectivity (Fig. 8d-i). Before the storm moved onto HB, the evolutions of radar reflectivity in $\mathrm{TmpN}$ and $\mathrm{TmpP}$ were similar to each other (Fig. 8d, g). After storm passing over HB, the radar reflectivity in TmpN weakened more quickly than that in TmpP (Fig. 8e, h). As the storm landed on the south shore, the radar reflectivity intensified in both experiments, which was the same as in CTRL (Figs. 8f, i and 7f). In TmpN, by decreasing SST over HB, convection over the HB was suppressed more significantly, and both the rainfall over the HB and on the south shore decreased, but the amplitude was very small (Fig. 10b). In TmpP there were more significant changes in spatial distribution of precipitation, especially along the south coastline (Fig. 10c). Moreover, the precipitation in the onshore along the coastline is strengthened, but weakened in offshore when the SST over HB is increased (Fig. 10c). The maximum precipitation in both TmpN and TmpP are similar to that in CTRL. However, the average precipitation and maximal wind speed in TmpP are slightly increased than those in TmpN (Table 3). Therefore, lower SST over the HB has a certain inhibitory effect on evolution of thunderstorms crossing 

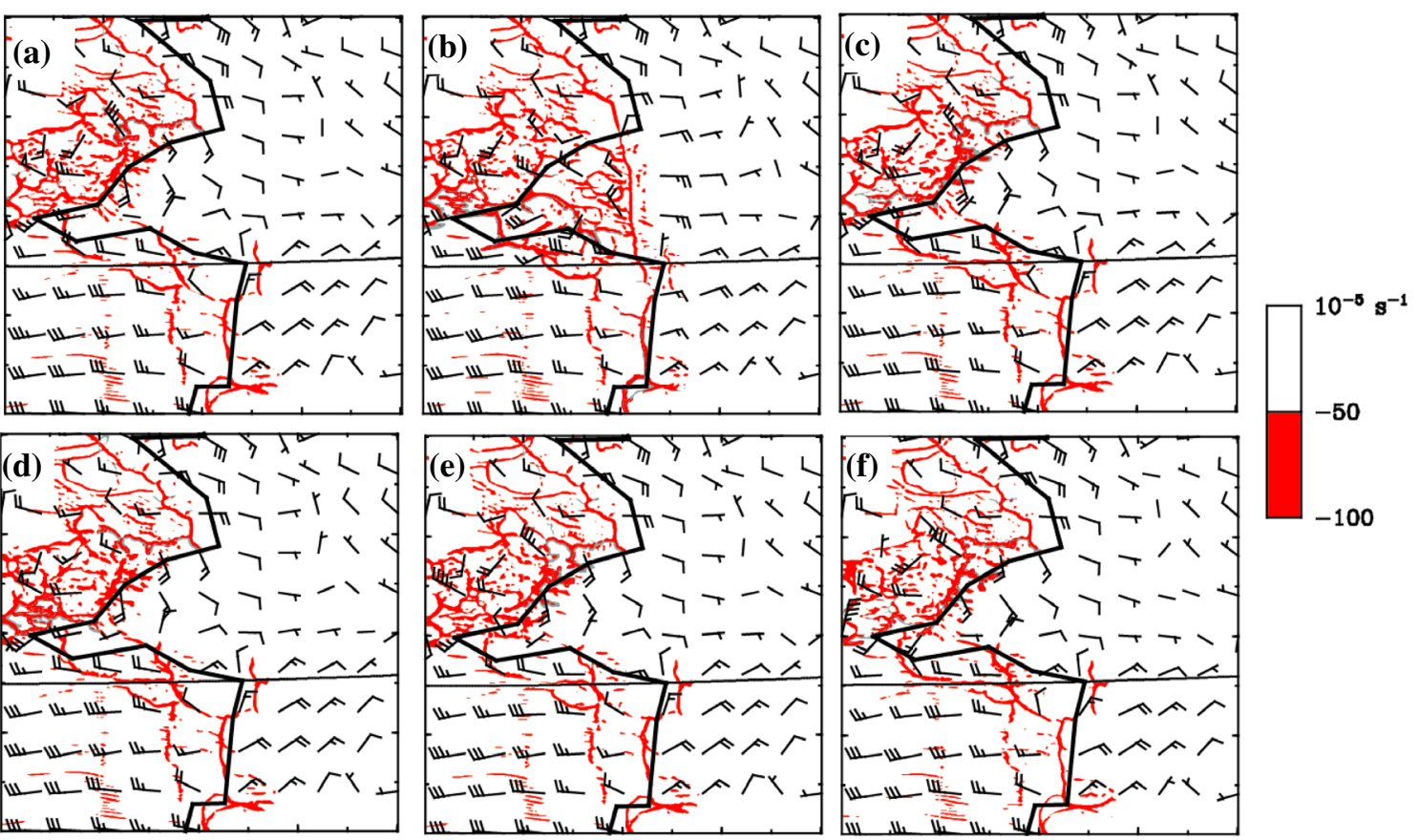

Fig. 9 Horizontal divergence on surface level $\left(\leq-50 \mathrm{~s}^{-1}\right.$ : shading; interval is $\left.50 \mathrm{~s}^{-1}\right)$ and 10-m horizontal wind speed (full bar for $\left.2 \mathrm{~ms}^{-1}\right)$. a CTRL, b NoBay, $\mathbf{c}$ TmpN, $\mathbf{d}$ TmpP, e Fric, and $\mathbf{f}$ Bogus at $2.5 \mathrm{~h}$ of integration (1630 LST)
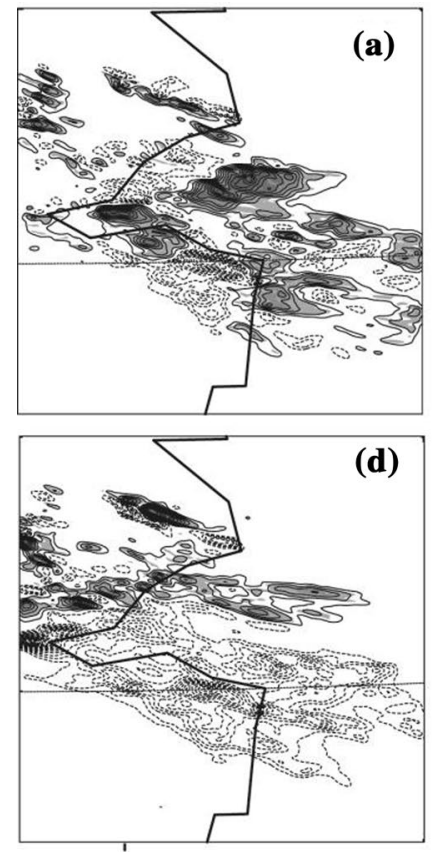

$121 \mathrm{E}$
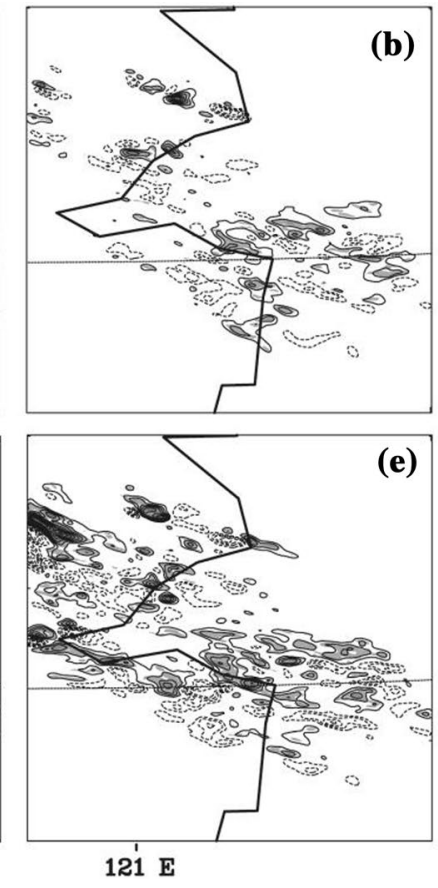

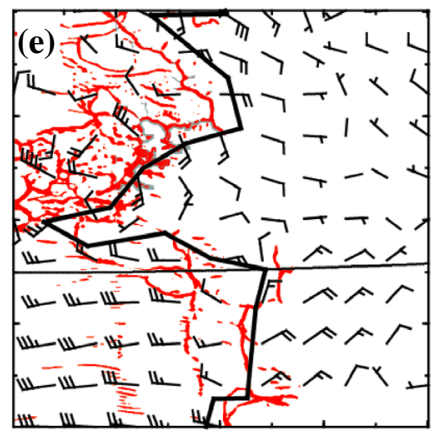


Table 3 The comparisons of simulated and observational average precipitation $\left(R_{\text {ave }}\right)$, maximal precipitation $\left(R_{\max }\right)$, and maximal wind speed $\left(U_{\max }\right)$ on the $100 \mathrm{~km}^{2}$ region around the radar station (location of star in Fig. 1a), from 1200 LST to 2000 LST 4 July 2010

\begin{tabular}{llll}
\hline Experiment & $R_{\text {ave }}(\mathrm{mm})$ & $R_{\max }(\mathrm{mm})$ & $U_{\max }\left(\mathrm{ms}^{-1}\right)$ \\
\hline CTRL & 17.7 & 52.7 & 12.2 \\
NoBay & 17.7 & 36.9 & 12.8 \\
TmpN & 16.6 & 58.2 & 13.6 \\
TmpP & 21.0 & 49.8 & 18.6 \\
Bogus & 18.1 & 50.1 & 13.4 \\
Fric & 13.5 & 42 & 8.4 \\
Obs & 26.2 & 42.7 & 17.4 \\
\hline
\end{tabular}

$\mathrm{HB}$, but a weak effect on the development of sea-land breeze (Fig. 8d, g).

To evaluate the impact of strength of sea-land breeze circulation on the convective systems around HB, two sensitivity experiments on low-level wind perturbation are performed. In experiment Fric, surface friction along the coastline is enhanced, resulting in the suppression on in-land intrusion of onshore sea-breeze and weakening of sea-land breeze circulation. In experiment Bogus, both sea-level pressure gradient and easterly wind speed were amplified to strengthen sea-land breeze. The radar reflectivity of Fric and 10-m horizontal wind difference between Fric and CTRL are shown in Fig. 8j-1. As shown in Fig. 7, the mean wind direction around HB was mainly easterly in CTRL. Caused by the decreasing of easterly land-sea breeze over the coastline regions, the wind difference between Fric and CTRL was mainly in the westerly direction (Fig. $8 \mathrm{j}-1$ ). Then, the convective systems in Fric might transfer offshore, and heavy precipitation was mainly located along the north coastal areas (Fig. 10d). On the other hand, convection over the center of HB and on the south coastline was both weakened and the weakening amplitude was much larger than that in TmpN. The average precipitation $(13.5 \mathrm{~mm})$ and maximal wind speed $\left(8.4 \mathrm{~ms}^{-1}\right)$ in Fric are both smaller than that in CTRL (Table 3).

In Bogus, through changing the initial pressure gradient force and easterly wind speed over HB, the land-sea-breeze circulation could be altered, as well as the spatial distribution of convection along the coastlines (Figs. 8m, 9f). Comparison with that in CTRL, convection systems were intensified in Bogus. Under the easterly wind, the amplification of precipitation on the north shore was more distinct than that on the south shore (Fig. 10e), but the changing of average precipitation around radar station area in south coast was very small.

In a short summary, these five sensitivity experiments indicate that the variations of the surface features of Hangzhou Bay have obvious impact on the intensity evolution of convective systems and the spatial distribution of precipitation.

\section{Discussion}

Previous studies indicated that the evolutions of thunderstorm and squall line are sensitive to CAPE and to environmental vertical wind shear (Rotunno et al. 1988; Weisman et al. 1988; Weisman and Rotunno 2004), both of which could be obviously influenced by sea-land contrasts. It was demonstrated by Scott and Huff (1996) that the Great Lakes suppress mesoscale convective systems and precipitation near the coastlines during summer, particularly in downwind regions of the lakes, and all lakes could cause a downwind decrease in rainfall by $10 \%-20 \%$. Parker (2008) found that in instances where the water surface is warmer than colder surface layer ahead of a storm, the storm can intensify.

In temperature perturbation experiments, i.e., TmpN and TmpP, the water surface temperature of HB was changed slightly to alter environmental parameters around the bay, such as sea-land temperature contrast, CAPE. However, the water surface was still colder than land. The air temperature above HB was altered through heat flux from water surface, which could influence the atmospheric buoyancy and then the evolution of convective systems. Figure 11 shows the surface heat flux differences between the five sensitive experiments and CTRL at 1800 LST 4 July 2010. In general, obvious impact on heat flux can be found over HB, while influences over inland areas were weaker. Similar as in e.g., Kehler-Poljak et al. (2017).

In NoBay, the whole HB is replaced by cropland. The surface temperature of the fake cropland in "true" HB is set to nearby surrounding seashore temperature, which was $6 \mathrm{~K}$ higher than HB's water temperature in CTRL. As a result, difference of surface upward heat flux between NoBay and CTRL was the biggest in all experiments, with the maximum difference exceeding $70 \mathrm{~W} \mathrm{~m}^{-2}$ (Fig. 11a). Similarly, the atmospheric instability energy in NoBay in the center of HB was also the highest, with the value of CAPE being $2571 \mathrm{Jkg}^{-1}$ exceeding that of CTRL $\left(2098 \mathrm{Jkg}^{-1}\right)$, and its LI was also higher than that in CTRL (Table 4). Heat flux was influenced by water surface temperature perturbation directly. For positive temperature perturbation in TmpP, surface heat flux was increased (Fig. 11c), which favored the development of convection. As for negative temperature perturbation, the results are opposite (Fig. 11b). Influenced by heat flux, the value of CAPE in TmpP increased obviously. For instance, TmpP had a CAPE of $2286 \mathrm{Jkg}^{-1}$ after $2.5 \mathrm{~h}$ of integration, which is larger than that of CTRL by $188 \mathrm{Jkg}^{-1}$ (Table 4). The convective inhibition (CIN) decreased from $34 \mathrm{Jkg}^{-1}$ in CTRL to $28 \mathrm{Jkg}^{-1}$ in TmpP. Similarly, both LI and precipitable water (PW) in TmpP also showed a more 
Fig. 11 Differences of surface upward heat flux between sensitivity experiments and control simulation (CTRL): a NoBay, b TmpN, c TmpP, d Fric, and e Bogus $\left(\geq 4 \mathrm{~W} \mathrm{~m}^{-2}\right.$ : shading; $\leq-4 \mathrm{~W} \mathrm{~m}^{-2}$ dashing; interval is $4 \mathrm{~W} \mathrm{~m}^{-2}$ ) at $4 \mathrm{~h}$ of integration (1800 LST 4 July 2010)

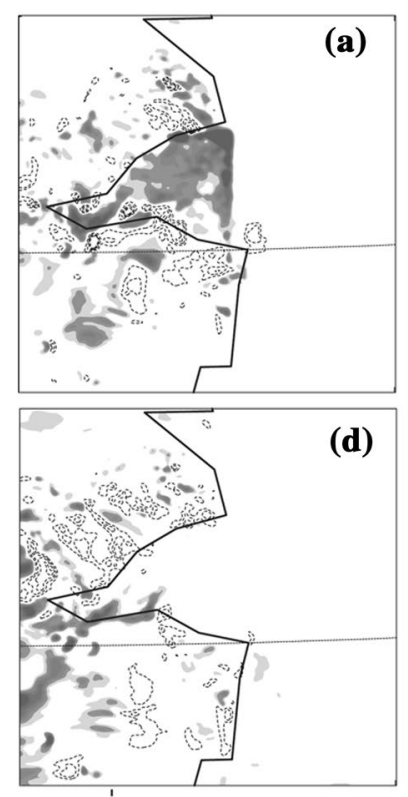

$121 \mathrm{E}$
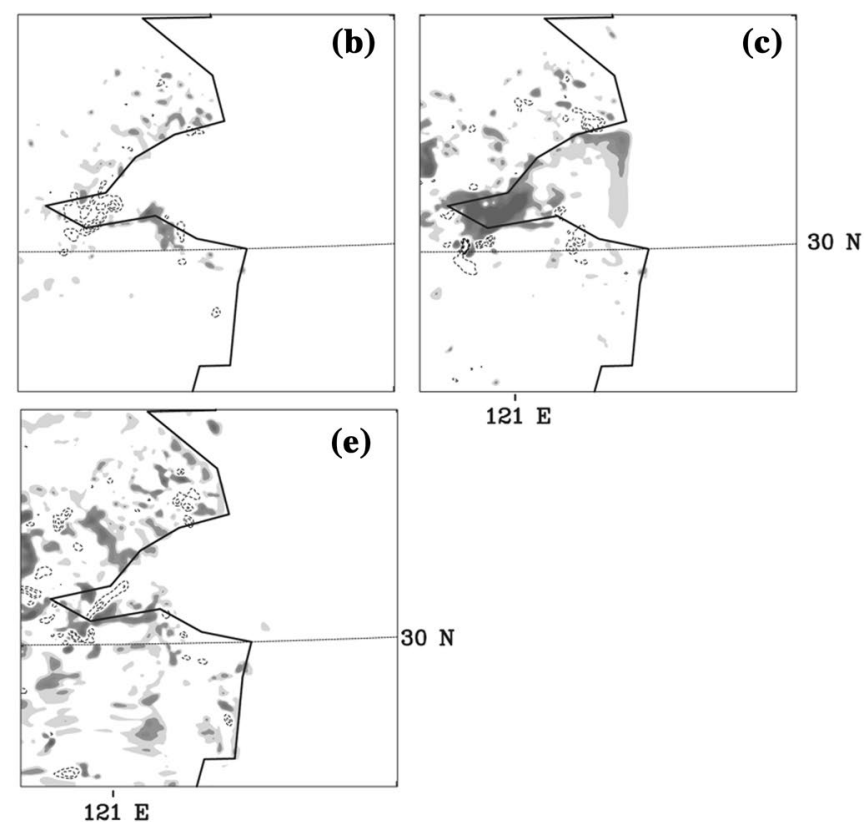

Table 4 Thermodynamic variables at point A in Fig. 1 at $2.5 \mathrm{~h}$ of integration (1630 LST) before the storm approached the Hangzhou Bay

\begin{tabular}{lllll}
\hline Experiment & CAPE $\left(\mathrm{Jkg}^{-1}\right)$ & $\mathrm{CIN}\left(\mathrm{Jkg}^{-1}\right)$ & $\mathrm{LI}(\mathrm{K})$ & PW $(\mathrm{cm})$ \\
\hline CTRL & 2098 & 34 & -4.4 & 7.69 \\
NoBay & 2571 & 42 & -4.9 & 7.72 \\
TmpN & 2086 & 34 & -4.2 & 7.65 \\
TmpP & 2286 & 28 & -4.5 & 7.72 \\
Bogus & 2048 & 35 & -4.1 & 7.53 \\
\hline
\end{tabular}

In the table, abbreviations represent: $C A P E$ convective available potential energy $\left(\mathrm{Jkg}^{-1}\right), C I N$ convective inhibition $\left(\mathrm{Jkg}^{-1}\right), L I$ lifted index $(\mathrm{K}), P W$ precipitable water $(\mathrm{cm})$

unstable tendency of the atmosphere. On the contrary, CAPE in TmpN decreased slightly with amplitude of only $12 \mathrm{Jkg}^{-1}$, and the CIN was almost unchanged. There was no linear relationship between temperature disturbance and heat flux change, because TmpP had a much larger heat flux change compared to TmpN (Fig. 11b, c). As a result, the unstable energy in TmpP changed more distinctly, and the energy change was mainly focused on CAPE; while CIN, LI and PW only varied slightly. In general, the lower the SST is, the smaller the CAPE will be. So, lower SST can increase the stability of the atmosphere and restrain convection. In the wind perturbation experiment, heat flux difference (Fig. 11d, e) mainly depended on the activity of convections. When convective actions were active, substantial clouds resulted in decreasing heat flux. As the convective systems traveled onto the cold bay, the inland clouds decreased, inducing the intensification of surface upward heat flux.
The boundary layer convergence zones caused by sea-land breeze on the north coastline have already combined with the outflow boundary of the thunderstorm by 1630 LST 4 July 2010 in CTRL. Therefore, there were many irregular convergence zones along the north coastline (Fig. 9a). Convergence zones around the south coastline can be divided into three pieces, which are caused by the irregular shape of the southern coastline. As shown in Figs. 6a and $9 \mathrm{a}$, heavy rainfall happened at the junction areas of the two BL convergence zones. The irregular coastline can affect the distribution of convective cloudiness and the amount of rainfall along a sea-breeze front (Neumann 1951; Purdom 1976; Baker et al. 2001). The initialized location and convective features of deep convection can be influenced by coastline shape, which then could impact the evolution of BL convergence zone (e.g., Abbs 1983). Boundary layer convergence also depends on sea-land temperature contrast and atmospheric circulation condition. When the water surface of $\mathrm{HB}$ is replaced by cropland, the "true" sea-land boundary is altered, resulting in obviously eastward shift of BL convergence zone (Fig. 9b). Along the new sea-land interface, a north-south sea-breeze front formed, which then led to an adjustment on thunderstorm evolution (Fig. 8b, c).

Temperature perturbation over the HB can induce changes to sea-land temperature difference and sea-land breeze's intensity, but it brought about little variation on the shape of BL convergence zone, and only impacted the spatial distribution and intensity of convergence zone very slightly. When the water surface temperature of $\mathrm{HB}$ was decreased in TmpN, BL convergence on the northern coastline almost did not change, while that on the southern coastline intensified (Fig. 9c). On the other hand, when 
positive temperature perturbation was added to the water surface temperature of $\mathrm{HB}$, the $\mathrm{BL}$ convergence zone on the north coastline moved offshore appreciably and that on the south coastline weakened slightly (Fig. 9d).
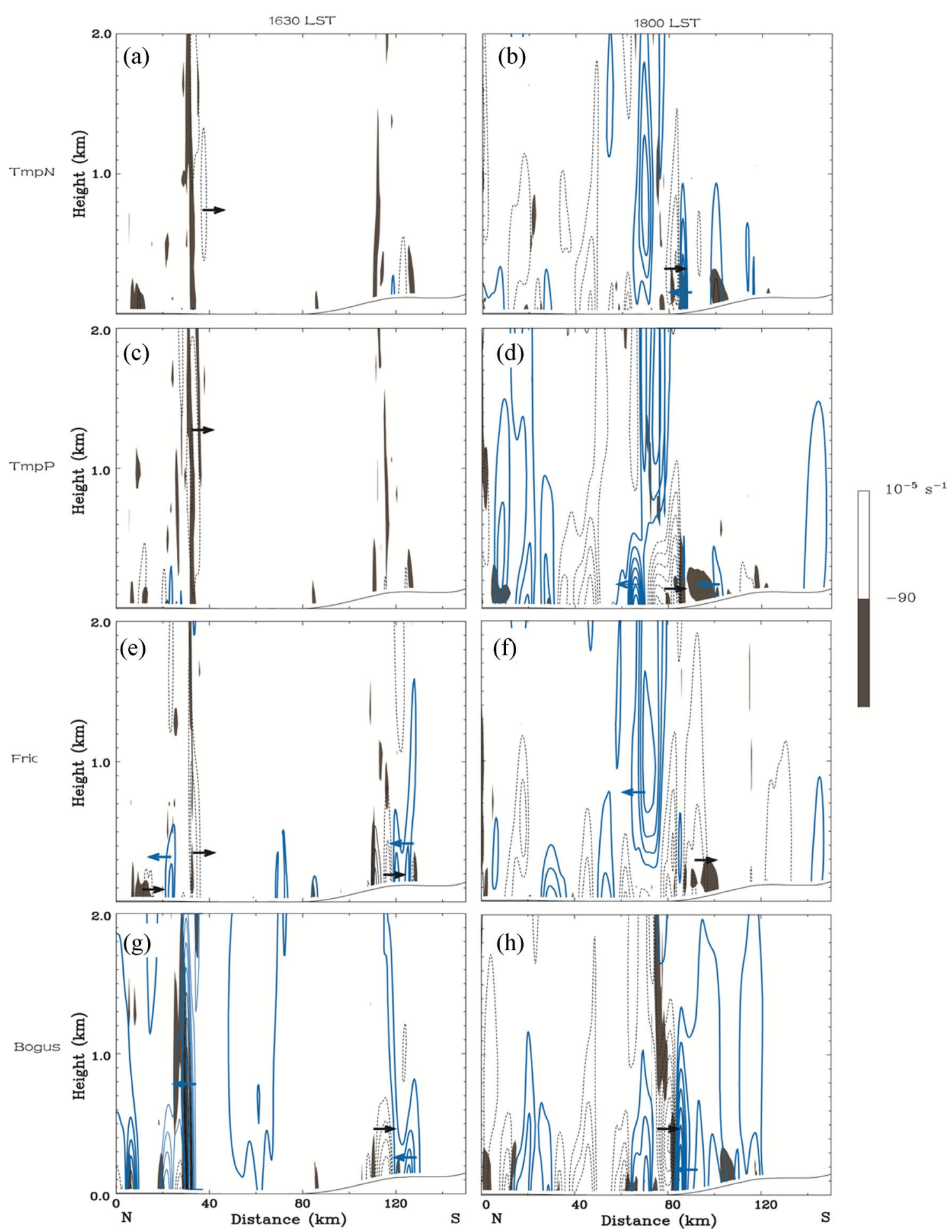

Fig. 12 Vertical distributions of meridional wind difference (blue contours with interval of $0.5 \mathrm{~ms}^{-1}$; negative values are dashed) between sensitivity experiments and control simulation (CTRL). $\mathbf{a}-\mathbf{b}$ : TmpN, c-d: TmpP, e-f: Fric, $\mathbf{g - h}$ :Bogus, and horizontal divergence

in sensitivity experiments ( $\leq-90 \mathrm{~s}^{-1}$, shading) along the south-north section crossing the center of Hangzhou Bay $\left(121.6^{\circ} \mathrm{E}\right)$ at 1630 and 1800 LST 4 July 2010 
Figure 12 shows that obvious BL convergence existed around HB. Temperature perturbation can influence lowlevel wind speed to alter the BL convergence, but the change at 1630 LST 4 July 2010 was very limited (Fig. 12a, c). On the north coast, the $\mathrm{BL}$ convergence in $\mathrm{TmpN}$ is much larger. Then, the convective systems developed rapidly and moved close to the southern coastline. At that time, low-level convergence (1800 LST; Fig. 12b, d) was formed mainly due to the co-effect of northerly wind from the outflow of the thunderstorm and the southerly wind on the southern coastal area of HB. Restrained by much colder water surface across $\mathrm{HB}$, the convection in TmpN were less active than those in TmpP as the storm moved near the southern coastline of HB. In addition, the intensity of both storm's outflow and BL convergence in $\mathrm{TmpN}$ was weaker compared with that in TmpP, resulting in much heavier precipitation in TmpP on the southern coastline (Fig. 10c, Table 3). The above discussions demonstrated that the boundary layer convergence along the coastline caused by sea-land breeze and the colder temperature of water surface can both impact the evolution of mesoscale convective systems crossing HB. The convective systems are intensified as the storm moved near the northern coastline of HB. After the storm moved to colder water surface, the convective actions were suppressed. When the storm made its landing on the southern coastline of $\mathrm{HB}$, its intensity would strengthen once more.

Besides sea-land temperature contrast, boundary layer convergence on coastal areas can also be impacted by onshore friction and atmospheric circulation conditions (Wexler 1946; Azorin-Molina et al. 2009; Poljak et al. 2014). The results of Fric indicated that BL convergence zone would move inland after the friction along the coastline was intensified (Fig. 12e). As a result, it introduced decreasing of easterly land-sea breeze over the coastline regions of HB. The offshore convergence was weakened because of the intensification of friction along the coastline, so that the weakening of the storm was very quickly across $\mathrm{HB}$, and this induced even more inhibition on precipitation near the southern coastline (Fig. 10d).

By enhancing easterly wind speed above HB in Bogus, the BL convergence intensified obviously (Fig. 12g, h). The cause was as follows: for organized convective systems, when the storm approached the southern coastline, BL convergence zones induced by sea-land breeze merged with storm's outflow convergence. As a result, the organized convective systems near the southern coastline intensified in Bogus (Fig. 8o). In a word, as the increasing of onshore easterly wind speed, stronger BL convergence could be triggered through comprehensive influences of sea-land breeze.

\section{Conclusions}

Statistically, the intensity of organized convective systems crossing over a large water body of Hangzhou Bay usually experiences a process of intensifying on the northern coastline, weakening over colder water body, and finally strengthening on the southern coastline during summer. To explore the mechanism accounting for such feature, a thunderstorm case passing through Hangzhou Bay on 1300 UTC 4 July, 2010 was simulated and analyzed. A series of sensitivity experiments were also carried out to explore the impact of the surface temperature and wind perturbations on the development of storm crossing Hangzhou Bay. The conclusions are as the following.

First, the water surface temperature has obvious influence on the storm intensity. When water surface temperature over Hangzhou Bay was decreased, the surface heat flux was also decreased leading to the weakening of the thunderstorm's intensity. As a result, boundary layer convergence and precipitation of the storm will be reduced at the time. When positive temperature perturbation is added on the water surface temperature of $\mathrm{HB}$, the inhibitive effects of cold surface on the development of storm were attenuated. Furthermore, there were positive influences on the intensification of precipitation when the thunderstorm landed on the south shore.

Second, the wind perturbations had also impact on the storm evolution. The intensification of the easterly wind will increase the boundary layer convergence, the increased convergence cooperated with the sea-land breeze will favor the development of the thunderstorm along the northern coastline. When the thunderstorm made landing on the south shore of $\mathrm{HB}$, the boundary layer convergence strengthened due to the merging of intensified storm's outflow with the sea-breeze convergence. As a result, the total rainfall was also enhanced.

In this paper, we just concerned about a single thunderstorm case. And through the numerical simulation of this case, the influence mechanism of the broad water surface of Hangzhou Bay on the development of convection was studied. In the next step, the separation of large-scale and mesoscale weather systems through composite analysis of several thunderstorm cases will be done to study the effect of sea-land breeze on the triggering and enhancement of thunderstorms. Besides, the effects of temperature difference between land and sea under different environmental background on development of thunderstorms convections passing over Hangzhou Bay are studied through the comparison analysis of different cases.

Acknowledgements The authors are grateful to the two anonymous reviewers for their precious suggestions. This work was supported by the National key R\&D Program of China (2017YFC1502501, 2017YFC1502502) and the National Natural Science Foundation of China (41405051, 41461164008, 41675053).

Open Access This article is distributed under the terms of the Creative Commons Attribution 4.0 International License (http://creativeco 
mmons.org/licenses/by/4.0/), which permits unrestricted use, distribution, and reproduction in any medium, provided you give appropriate credit to the original author(s) and the source, provide a link to the Creative Commons license, and indicate if changes were made.

\section{References}

Abbs DJ (1983) Sea-breeze interactions along a concave coastline in southern Australia: observations and numerical modeling study. J Atmos Sci 40:1999-2009

Augustine JA, Woodley WL, Scott RW, Changnon SA (1994) Using geosynchronous satellite imagery to estimate summer-season rainfall over the great lakes. J Great Lakes Res 20:683-700

Azorin-Molina C, Connell BH, Baena-Calatrava R (2009) Sea-breeze convergence zones from A VHRR over the Iberian Mediterranean area and the Isle of Mallorca, Spain. J Appl Meteor 48:2069-2085

Baker RD, Lynn BH, Boone A, Tao WK, Simpson J (2001) The influence of soil moisture, coastline curvature, and land-breeze circulations on sea-breeze-initiated precipitation. J Hydrometeor 2:193-211

Byers HR, Rodebush HR (1948) Causes of thunderstorms of the Florida peninsula. J Atmos Sci 5:275-280

Comin AN, Miglietta MM, Rizza U, Acevedo OC, Degrazia GA (2015) Investigation of sea-breeze convergence in Salento Peninsula (southeastern Italy). Atmos Res 160:68-79

Hong SY, Noh Y, Dudhia J (2006) A new vertical diffusion package with an explicit treatment of entrainment processes. Mon Wea Rev 134:2318-2341

Kain JS (2004) The Kain-Fritsch convective parameterization: an update. J Appl Meteor 43:170-181

Kain JS, Fritsch JM (1990) A one-dimensional entraining/detraining plume model and its application in convective parameterization. J Atmos Sci 47:2784-2802

Kain JS, Fritsch JM (1993) Convective parameterization for mesoscale models: The Kain-Fritcsh scheme. Meteor Monogr 24:165-170

Kehler-Poljak G, Telišman Prtenjak M, Kvakić M, Šariri K, Večenaj $\check{Z}$ (2017) Interaction of sea breeze and deep convection over the northeastern Adriatic coast: an analysis of sensitivity experiments using a high-resolution mesoscale model. Pure Appl Geophys 174:4197-4224

King PWS, Leduc MJ, Sills DML, Donaldson NR, Hudak DR, Joe P, Murphy BP (2003) Lake breezes in southern Ontario and their relation to tornado climatology. Wea Forecasting 18:795-807
Leopold LB (1949) The interaction of trade wind and sea breeze, Hawaii. J Atmos Sci 6:312-320

Lericos TP, Fuelberg HE, Weisman ML, Watson AI (2007) Numerical simulations of the effects of coastlines on the evolution of strong, long-lived squall lines. Mon Wea Rev 135:1710-1731

Mazón J, Pino D (2013) The role of sea-land air thermal difference, shape of the coastline and sea surface temperature in the nocturnal offshore convection. Tellus 65A:20027. https://doi.org/10.3402/ tellusa.v65i0.20027

Neumann J (1951) Land breezes and nocturnal thunderstorms. J Meteor 8:60-67

Ogura Y, Chen YL (1977) A life history of an intense mesoscale convective storm in Oklahoma. J Atmos Sci 34:1458-1476

Parker MD (2008) Response of simulated squall lines to low-level cooling. J Atmos Sci 65:1323-1341

Pielke RA (1974) A three-dimensional numerical model of the sea breezes over south Florida. Mon Wea Rev 102:115-139

Poljak G, Prtenjak MT, Kvakić M, Strelec-Mahović N, Babić K (2014) Wind patterns associated with the development of daytime thunderstorms over Istria. Ann Geophys 32:401-420

Purdom JFW (1976) Some uses of high-resolution GOES imagery in the mesoscale forecasting of convection and its behavior. Mon Wea Rev 104:1474-1483

Rotunno R, Klemp JB, Weisman ML (1988) A theory for strong, longlived squall lines. J Atmos Sci 45:463-485

Scott RW, Huff FA (1996) Impacts of the great lakes on regional climate conditions. J Great Lakes Res 22:845-863

Simpson JE (1994) Sea breeze and local winds. Cambridge University Press, Cambridge

Thompson G, Field PR, Hall WD, Rasmussen RM (2008) Explicit forecasts of winter precipitation using an improved bulk microphysics scheme. Part II: implementation of a new snow parameterization. Mon Wea Rev 136:5095-5115

Weisman ML, Rotunno R (2004) "A theory for strong long-lived squall lines" revisited. J Atmos Sci 61:361-382

Weisman ML, Klemp JB, Rotunno R (1988) Structure and evolution of numerically simulated squall lines. J Atmos Sci 45:1990-2013

Wexler R (1946) Theory and observations of land and sea breezes. Bull Amer Meteor Soc 27:272-287

Wilson JW, Schreiber WE (1986) Initiation of convective storms at radar-observed boundary-layer convergence lines. Mon Wea Rev 114:2516-2536

Workoff T, Kristovich D, Laird N, LaPlante R, Leins D (2012) Influence of the Lake Erie over-lake boundary layer on deep convective storm evolution. Wea Forecasting 27:1279-1289 